\title{
Dynamics of physical fitness of students of Kurgan State University in the RLD system
}

\author{
Oksana Lovygina ${ }^{1}$, Irina Botova $^{2}$, Koryukin Dmitry ${ }^{3} *$, Nina Grebenshchikova ${ }^{4}$ \\ ${ }^{1}$ Associate Professor, Department of Physical Culture and Sports, Kurgan State University, 640000, Kurgan, Russia \\ ${ }^{2}$ Senior Teacher, Department of Physical Education and Sports, Kurgan State University, 640000, Kurgan, Russia \\ ${ }^{3}$ Head of the Department of Physical Education and Sports, Kurgan State University, 640000, Kurgan, Russia \\ ${ }^{4}$ Senior Teacher, Department of Physical Education and Sports, Kurgan State University, 640000, Kurgan, Russia
}

\begin{abstract}
The article presents the results of observations of the general physical fitness of male students of Kurgan State University. Deterioration of the physical fitness was observed in the 2011 - 2012 academic year. In the subsequent academic years, there were changes in the general physical fitness of male students. The article shows that since 2013 the physical fitness as an external feature of body functions has improved.
\end{abstract}

\section{Introduction}

Physical culture is part of general culture aimed at the harmonious development of personality with the help of special motor activities. In higher education, physical culture serves to form general and professional culture of a student; it contributes to the health, improves physical, functional, and psychological state. Health is the first and most important human need. Physical culture as a research subject was analyzed by many experts in physiology, medicine, psychology, etc. (B.K. Balsevich [1], M.Ya. Vilensky [2], R.Kh. Mitrichenko [3], V.A. Kurentsov [4], A.S. Dvornikova, N.E. Kurochkina [5], Polkova K.A. [6] and many others). As an academic discipline, physical education is mandatory. In accordance with the state educational standard of higher professional education (FSES 3,3+) and the standard of higher education (FSES $3++$ ), 328 academic hours are allocated for physical culture [7].

The research purpose and methods.

The purpose of this article is to identify the dynamics of the general physical fitness of male students of Kurgan State University.

The research is a process of physical education of students; the research subject is physical fitness of male students.

\section{Materials and methods}

The study involved young students aged 18 to 21 who have been studying at Kurgan State University (KSU) from 2010 to 2019 in the following departments: historical, economic, pedagogical, mathematics and information technology, transport systems.
According to the doctor's opinion, all the male students were referred to the main medical group. During their diagnostics, there were no health complaints.

To achieve the research purpose, the following methods were used: control tests and the mathematicalstatistical method. To determine the physical fitness of male students of Kurgan State University, the test method was used. It consisted of the following tests: a standing long jump $(\mathrm{cm})$, raising legs to touch the crossbar in hanging (number of times), pulling up from a high crossbar), 100-meter running (sec). Tests were performed by all students in the same conditions at KSU sports facility, twice a year (September - October and April May); the best result of each student was taken into account.

The mathematical statistical method was used to process the data. The data were processed by parametric statistics methods in Microsoft Excel.

\section{Results}

In the "standing long jump" test, the average values for the studied period ranged from $222.54 \pm 1.68 \mathrm{~cm}$ to $231.79 \pm 1.66 \mathrm{~cm}$ (Fig. 1). The minimum result was observed in the 2011-2012 academic year; in the next academic year, a sharp increase to $230.11 \pm 8.09 \mathrm{~cm}$ was recorded. Since the 2013-2014 academic year, a gradual increase in results begins with slight fluctuations, and the maximum result was recorded in the 2018 - 2019 academic year $(231.79 \pm 1.66 \mathrm{~cm})$.

\footnotetext{
* Corresponding author: krjukin.dimn@mail.ru
} 


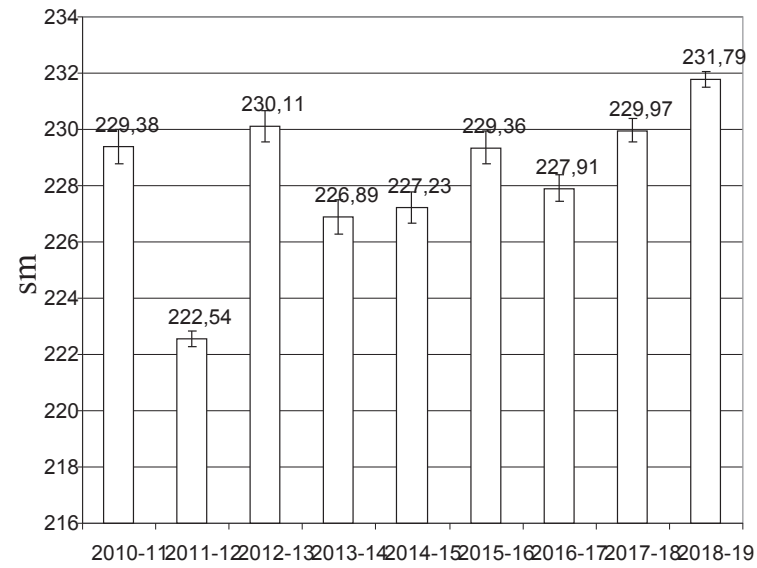

Academic year

Fig. 1. The average results of the test "standing long jump"

In the "raising legs to touch the crossbar", the least value was recorded in the 2011-2012 academic year $6,82 \pm 0,89$ pas (Fig. 2). Since the $2012-2013$ academic year, a wave increase in values was recorded. The maximum value $(9,64 \pm 0,74$ times $)$ was recorded in the 2018 - 2019 academic year. Thus, force capabilities if male students have increased.

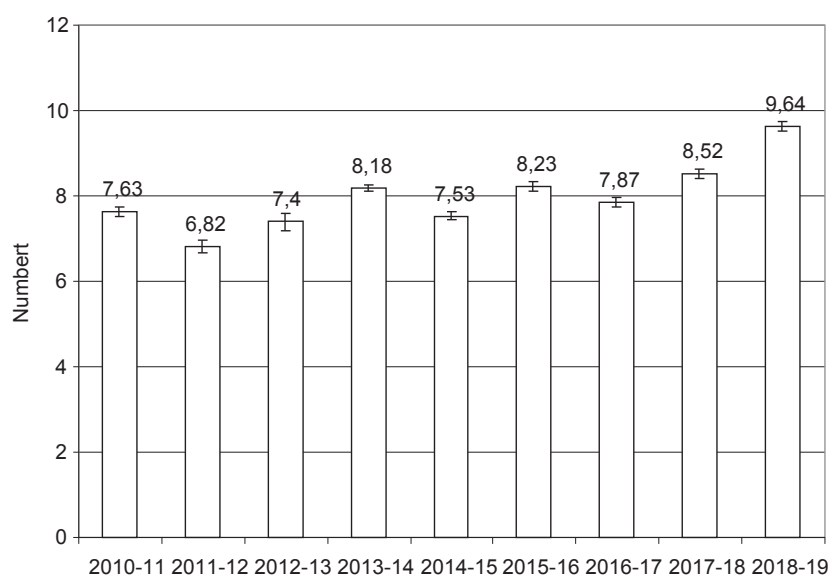

Academic year

Fig. 2. The average results of the test "raising legs to touch the pull-bar in hanging"

Pulling up in hanging reflects a degree of development of strength endurance of the upper shoulder girdle. At the beginning of the study, the average value was $9.74 \pm 0.53$ times; in the 2011-2012 academic year, the minimum value was $8.78 \pm 0.84$ times (Fig. 3). In the 2012-2013 academic year, the male students were able to pull up $10.52 \pm 2.24$ on a high crossbar. In the next academic year, a decrease in the values was observed; in the subsequent years, the values increased. The maximum values were reached in the 2018 - 2019 academic year $(12.05 \pm 1.4$ times).

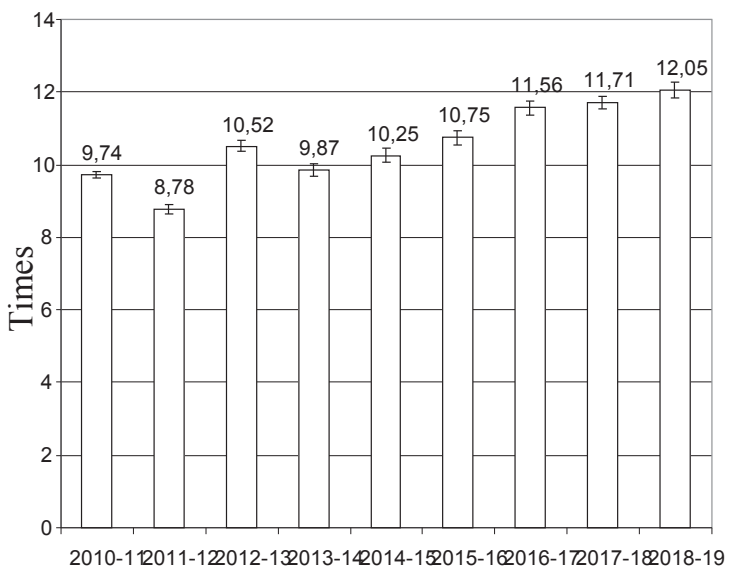

Academic year

Fig. 3. The average results of the test "5Pulling up"

The classic test for determining speed abilities is a 100 -meter run. The worst result was recorded in the 20112012 academic year (15.74 \pm 1.51 seconds) (Fig. 4). Since 2012, there has been an increase in results; the best result was recorded in the 2013-2014 academic year, when students managed to overcome a distance of 100 meters for $13.67 \pm 0.27$ seconds. During further observation, the average results ranged from $13.84 \pm 0.14$ to $14.23 \pm 0.09$ seconds.

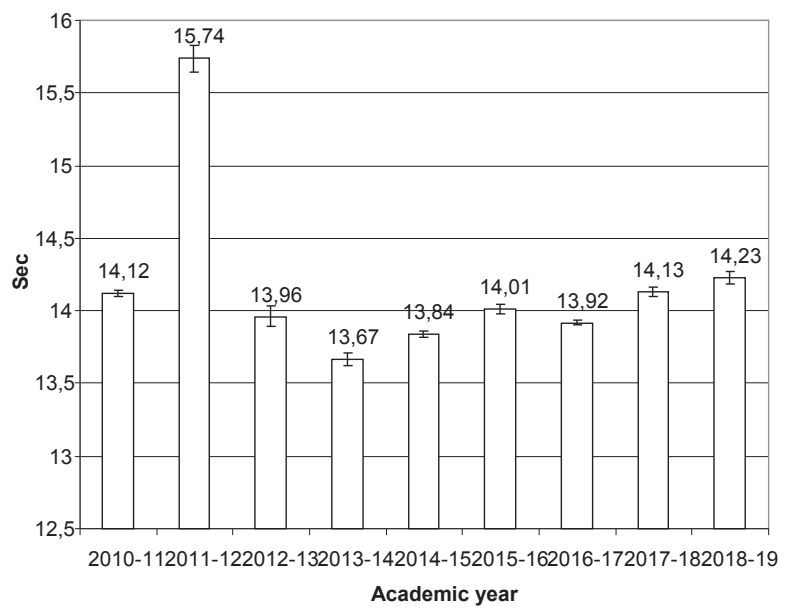

Fig. 4. Average results of the test "100 m running"

An analysis of the results shows that in the 2011-2012 academic year, the worst results were recorded for all the tests. Since the next academic year, the results have improved (Fig. 5, 6) due to the fact that on March 24, 2014, Presidential Decree No. 172 "On the All-Russian Sports and Fitness Complex "Ready for Labor and Defense" (TRP)" was issued. Its purpose is to increase the role of physical culture and sports in promoting health, harmonious and comprehensive development, raising patriotism and ensuring continuity in the physical 
education. One of the tasks is to increase the level of physical fitness. Educational institutions of all levels pay more attention to physical culture; the citizens of the Russian Federation are interested in improving physical fitness in order to comply with the RLD standards.

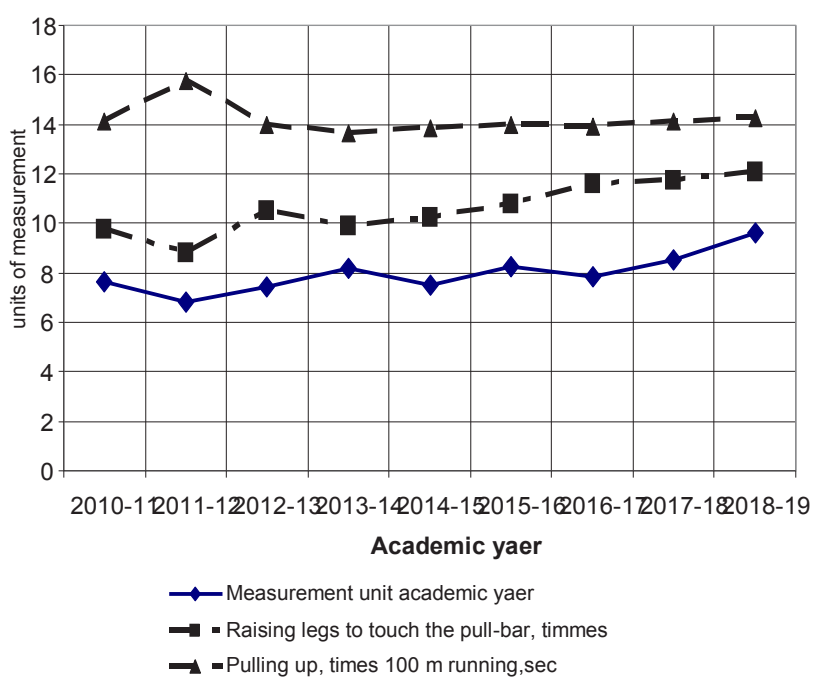

Fig. 5. Dynamics of the results general physical fitness tests in male students of KSU

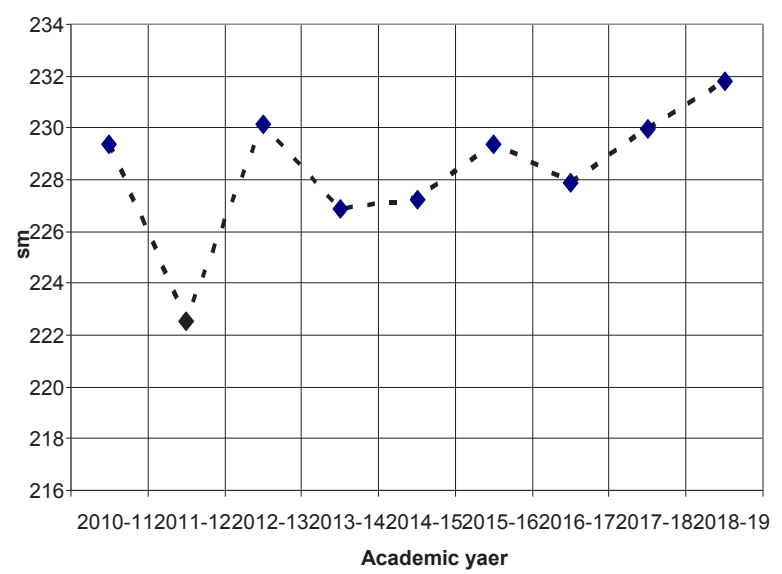

Fig. 6. Dynamics of the results of the "standing long jump" test in male students of KSU

\section{Discussion}

Physical fitness reflects the level of development of physical qualities (strength, speed, endurance, flexibility, dexterity), motor skills and skills required for certain activities. External manifestations of physical fitness are functions of the body systems, activities of the musculoskeletal, respiratory, cardiovascular, nervous and other systems.

Movement is a natural biological stimulator of physiological functions of the body. During motor activities, the flow of proprioceptive impulses increases, which increases the activity of the internal organs to ensure the normal functions of the muscles. Due to the systematic physical training and sports, coordination of the musculoskeletal system, internal organs and systems can be enhanced. It can improve physical health, the functional state of organs and body systems and the level of physical fitness, ensure effective adaptation to the environment.

The data of long-term observation show that since 2013, the functional state of the main systems of the body of male students aged 18-21 has improved. This assumption requires further study.

The gradual positive dynamics of the general physical fitness is due to the attention paid to physical culture and sports. In 2014, the federal programs "Development of physical culture and sports", "Healthcare Development", "All-Russian sports and fitness complex 'Ready for Labor and Defense' were adopted.

The article analyzes the dynamics of physical fitness of students in 2010 - 2011. Since 2011, the system of education in higher educational institutions has shifted to new Federal Educational Standards which are based on a competence-based approach to education. According to the European qualifications system, a competence is an integrated concept expressing an ability to apply various elements of knowledge and skills in a specific context [8]. Physical culture as an academic discipline was referred to the group of general cultural competences. In the previous FSES, this discipline was part of the "General Humanitarian and Socio-Economic Disciplines" cycle. Due to the transition to a new educational standard, the number of hours for this discipline changed: 400 hours instead of 408 hours.

In 2014, the Federal State Educational Standard 3+ was approved. 400 hours (including 360 hours of game training) and two credit units were allocated for "Physical Culture". In practice, the academic discipline "physical culture" was divided into two disciplines: "physical culture" (72 academic hours for lectures and seminars, and 328 hours for physical exercises).

\section{Conclusion}

Thus, the third-generation Federal State educational standards were created to move to a new level of graduate training that would meet international educational standards.

1. Long-term observations of the general physical fitness of students of Kurgan State University showed that in the 2011-2012 academic year, the worst results were observed for all the tests.

2. Since the 2012-2013 academic year, test results have improved.

3. According to the "100-meter run" test, the best result was observed in the 2013-2014 academic year; in the subsequent years, the results were worse.

4. Improvement of the general physical fitness of 18-21year-old male students indicates improvement of their physical health.

\section{References}

1. B.K. Balsevich. The Concept of Alternative Forms of Organization of Physical Education of Children and 
Youth, Physical Culture and Upbringing, Education, Training, 2, (1996).

2. M.Ya. Vilensky Student as a subject of physical culture, Theory and practice of physical culture. 10., 2-5, (1999)

3. R.Kh. Mitrichenko model of the organization of recreational classes in physical culture of students of higher educational institutions: Thesis, VGAFK., 27, (2012)

4. V.A. Kurentsov Investigation of factors limiting the adaptation of young people to their upcoming professional activities at the initial stage of training. Physical education and youth sport. 1, 57-63., 2015
5. A.S. Dvornikova, N.E. Kurochkina, Physical fitness of students as an element of the professional culture of a future specialist, Humanities: Coll. Art. according to mat. LVIII int. stud scientific-practical conf. 10 (58). 65-67, (2017)

6. K.A. Polkova Physical fitness of students of TI $(F)$ $N E F U$ in subjective and objective indicators, International Student Scientific Journal. 3. (2017)

7. Federal State Educational Standards, Retrieved from: https://fgos.ru/ (2019)

8. European qualifications system, Retrieved from: https://bsu.by/cache/Page/172163.pdf (2019) 